\title{
High Speed Selective Brush Plating of Gold
}

\author{
advantages over conventional plating \\ IN SPECIFIC APPLICATIONS
}

\author{
Marv Rubinstein \\ Selectrons Limited, New York \\ The major proportion of all gold plating will always be carried out in \\ a conventional bath, but for a substantial number of industrial applica- \\ tions selective brush plating offers considerable savings.
}

Most gold platers are familiar with selective plating, a technique also known as doctoring or as brush, swab, touch-up, stylus and tampon plating. Selective plating is a true electrodeposition technique, although in appearance more closely resembling arc welding. A power supply provides D.C. current through two flexible cables, the cathodic one clamped to the work and the anodic cable plugged into a special working tool called a stylus, brush, or spatula. The most upto-date tool, the stylus, has an anode wrapped with absorbent cotton or covered with a Dacron jacket. This is immersed in a special high speed selective plating solution, or the electrolyte is flowed or pumped to the swab. The wrapped anode, saturated with solution, is moved over the surface to be plated, thus completing the circuit, as shown in Figure 1. Gold or other metals are deposited from the swab.

\section{Advantages and Limitations}

In general, given the choice between conventional bath plating and selective plating, bath plating should always be used unless some special advantage in quality, time, convenience or cost can be achieved using selective plating. For large scale bulk production, conventional electroplating is almost always cheaper and more convenient.

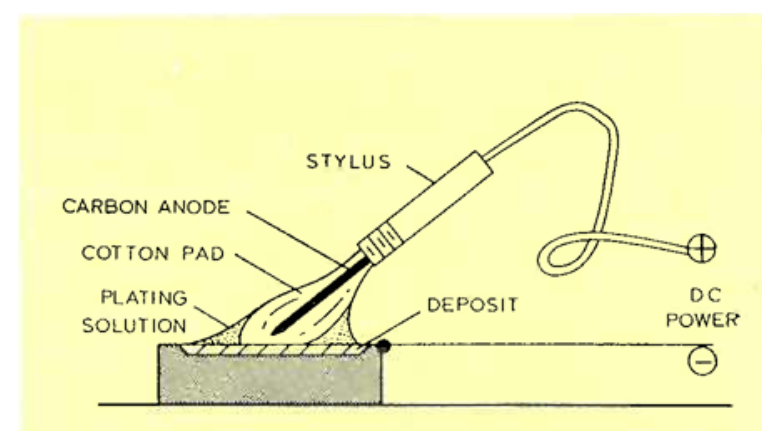

Fig. I Schematic diagram illustrating the principle of selective brush plating
In carrying out a cost analysis, however, the plater should take all production factors into account: a true comparison can only be made if costs such as disassembly, reassembly, masking, jigging, packing, transport and paper work are included. The possibilities of mechanising or automating selective plating to reduce labour costs should also be considered.

Summarising, probably 95 to 98 per cent of all plating will continue to be done in a bath. In an industrial society, the remaining 2 to 5 per cent of applications, however, constitute a substantial number of applications where selective plating can save money and (perhaps more importantly) time. The table lists nine areas where economies can be realised through the use of high speed selective plating.

\section{Printed Circuits}

Probably the most widely used application for selective gold plating is in the manufacture and repair of printed circuits and related printed wiring. General Electric NASA Division in the U.S.A. claimed savings upwards of $\$ 344,000$ by using this technique for circuit maintenance. Similar savings are documented by such companies as I.B.M., Litton Industries and Collins Radio. Typical printed circuit applications are as follows:

1 Repair of gold plating on edge contacts or fingers of assembled circuit boards without disassembly.

2 Economical small scale production plating of specialised printed circuits in lots up to 300 per day.

3 Selective plating of easily contaminated flexible circuitry and tape cable.

4 Prototype manufacture.

Edge Connector Contact Tabs

When the gold on edge contacts of assembled circuit cards has flaked or peeled, it is too late to replate these in a bath. Immersion in an electrolyte would contaminate assembled components. By shorting the edge contacts, they can readily be selectively 
plated without endangering the assembly (see Figure 2). In a similar case, the original plating may be excellent, but after a number of boards have been manufactured and assembled a change in specifications is introduced. The extra thickness of gold required may be selectively deposited.

In this procedure all loose or defective electroplating must first be removed; the edge contacts must then be shorted, the area selectively electrocleaned and plated. To avoid endangering neighbouring components rinsing is sometimes carried out with a small sponge.

\section{Flexible Circuits}

Flexible circuits and tape cable, when bath plated, present special problems. Flexing of the circuit imparts microscopic cracks between the conductive copper and the underlying plastic. With tape cable, sections are often cut to size and the plastic cover removed at both ends to expose contact areas. This results in weakening the bond between copper and underlying plastic. For both flexible circuitry and tape cable, the presence of microscopic gaps creates difficulties. Solutions are 'sucked' into these openings and trapped. No amount of rinsing completely removes them, and residual plating solutions later cause 'sweating', corrosion and changes in conductivity.

Selective plating avoids this problem. Without immersion, there is no hydrostatic pressure to 'push' the solution into the openings. Time required is appreciably less than that for bath plating, and consequently there is less time for solution to be entrapped. Finally, the very low free cyanide content (less than $0.5 \mathrm{~g} / 1$ ) of selective gold plating solutions creates fewer corrosion problems. A number of flexible

\section{Table}

Major Families of Selective Brush Plating Applications

1 Repair of defective or missing electroplate

2 Partnership applications (e.g. bath plus selective plating)

3 Components which become contaminated if immersed in an electrolyte

4 Parts too large for readily available facilities

5 Parts requiring costly disassembly, reassembly and/or handling

6 Parts needing considerable masking before bath plating

7 Improving adhesion to aluminium, stainless steel, carbon and refractory metals

8 Plating ultra-high strength steels with minimal hydrogen embrittlement

9 On-site plating in the field

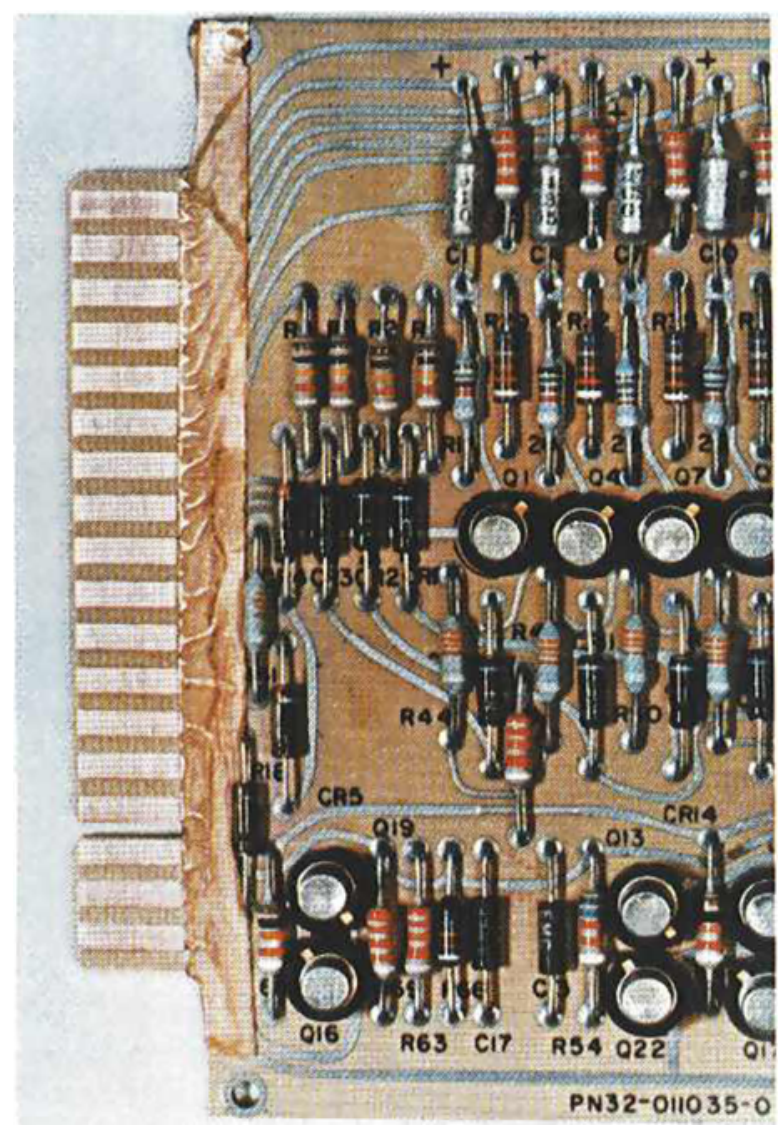

Fig. 2 A typical printed circuit card from the tabs or contacts of which defective gold has been removed. The contacts have then been shorted using a copper tape, conductive on both sides. The circuit is now ready for selective gold plating

circuit and tape manufacturers, with previous reject rates up to 30 per cent, have reduced this figure to zero.

\section{Electrical Contacts}

Replating gold on worn or damaged electrical contacts not easily removable provides another excellent application. Attempts to replate them in a bath, without disassembly, results in contamination of neighbouring components as well as waste of gold on non-essential areas.

A typical contact repair was carried out in the United States by Remington Rand Univac. In some of their earlier computer models they experienced difficulties with changes in electrical conductivity caused by corrosion after gold plating had worn off the pyramid-shaped electrical contacts. By the time this problem was corrected, connections had already been assembled into vast batteries of electrical contacts on computer units in the field.

These studs were selectively plated using a small hand-held electrical drill with a shaped carbon anode substituted for the bit. A Dacron felt liner covered 
the end. The anode tip was dipped into gold plating solution and contact was established with the male stud, while the drill rotated at a preset speed. A small foot pedal controlled electrical timer signalled the length of time required. A skilled operator could do thousands of contacts per day, depositing approximately 0.00005 inch of gold on each stud in six seconds. When a bell rang, the operator would merely re-dip the tip of his anode into the solution, re-establish contact at a new point and restart the drill.

Some of the added advantages of gold plating connector pins are indicated by the history of an altimeter servo unit manufactured by Litton Industries. Since this device was to be used in an early warning missile system, reliability was of the utmost importance. Consequently, the U.S. Government had a 23-hour test specification. During testing, a male connector plug was subjected to numerous insertions and withdrawals. The gold plating frequently failed. Previous repair involved removal of the plug and replacement with a new assembly. However, specifications state that any time any single component is replaced, the 23-hour test cycle must be repeated. Now, with selective plating, defective plate is removed from the pins using a wire brush, and fresh gold is replated without removing the component. Strictly speaking, no single component has been replaced in the assembly, and there is no need to repeat the lengthy test cycle-a major logistic benefit.

\section{Improving Solderability}

Certain metals, such as aluminium and stainless steel, provide soldering difficulties. Contaminating acid type fluxes, normally required for soldering, are forbidden in the electronics field. Selective plating avoids this difficulty and is widely used to improve solderability to aluminium and stainless steel, as well as on carbon, semiconductors and refractory metals. The particular base metal is cleaned, activated and a thin film of nickel or cobalt (from 0.0003 to 0.001 inch) plated, followed by a flash deposit of approximately 0.00003 inch of gold. Since adhesion of all these materials to the base is excellent, a gold surface intimately bonded to the underlying metal is obtained. Gold can easily be soldered with a neutral flux.

\section{Plastic Moulding}

With the increasing use of polyvinyl chloride (PVC) and polyvinylidene chloride (PVDC) for containers and bottles, special production problems occur. These polymers liberate minute quantities of hydrochloric acid, which tend to etch or pit the die cavities. This causes rejects due to drag marks and also shortens the life of moulds and dies.
A simple solution is selectively to plate these mould surfaces with a thin 0.0001 inch deposit of a hard gold alloy (140 to 160 Knoop) highly resistant to hydrochloric acid attack, as shown in Figure 3. This prevents penetration of the hydrochloric acid released by the PVC and considerably increases mould life. Selective repairs to the gold plate itself can readily be made while the mould is still in the machine.

Selective gold plating of moulds provides an additional advantage in situations where the plastic material tends to stick to the mould itself. Teflon moulding is typical. A flash deposit of gold provides a non-sticking surface. The problem of sticking exists in plastic extrusion as well, and gold flashing of extruder nozzles for C.B.S. Manufacturing Company has provided excellent results in preventing sticking.

\section{Aircraft and Marine Maintenance}

Specific uses are found in the maintenance depots of almost every commercial airline and Air Force station in the U.S.A. and Europe. Numerous marine maintenance depots, both commercial and Naval, are also starting to find this technique valuable, particularly for saving down-time.

Most aircraft and marine plating applications involve the use of cadmium, nickel, copper and tin. For certain specialised work, however, selective gold plating has also proved valuable. For example, contact areas on the slip ring of the ADF Loop Collector on Douglas DC-8 and Boeing B-720 aircraft have been replated with gold, as have numerous similar components.

Gears, bearings, bushing and cylinder liners of aircraft engine components are often selectively silver plated to prevent galling and fretting or to provide an interference fit. Selective gold is always used as a flash pre-plate. On the Douglas DC-8, gold-plussilver has been used to repair piston head grooves on the main gear door activator piston rod and the internal diameters of worn gland piston rod bores on aileron hydraulic power unit glands. On Pratt \& Whitney JT3D, JT4 and JT8D aircraft engines, goldplus-silver has selectively built up internal diameters on worn cylinder bushings, cover bushings, corroded and undersized main accessory drive gear box liner bores and worn seal lands of bearing nozzle assemblies. Similar deposits on outside diameters of bearing oil transfer tubes, worn journals where adaptor mates with gear drive, and on pressure ratio control yoke shafts have brought these parts back to original dimensions or have enabled interference fits to be obtained.

Other important aircraft work for gold plating involves improving wear on copper commutators for the many high speed servo-motors used throughout an aircraft. A flash of gold over a highly finished 
Fig. 3 A split die for blow moulding PVC containers receives a final deposition of hard gold by means of selective plating. By guarding against hydrochloric acid released during moulding, mould life is considerably extended, down-time is reduced, and a better product at lower cost is achieved

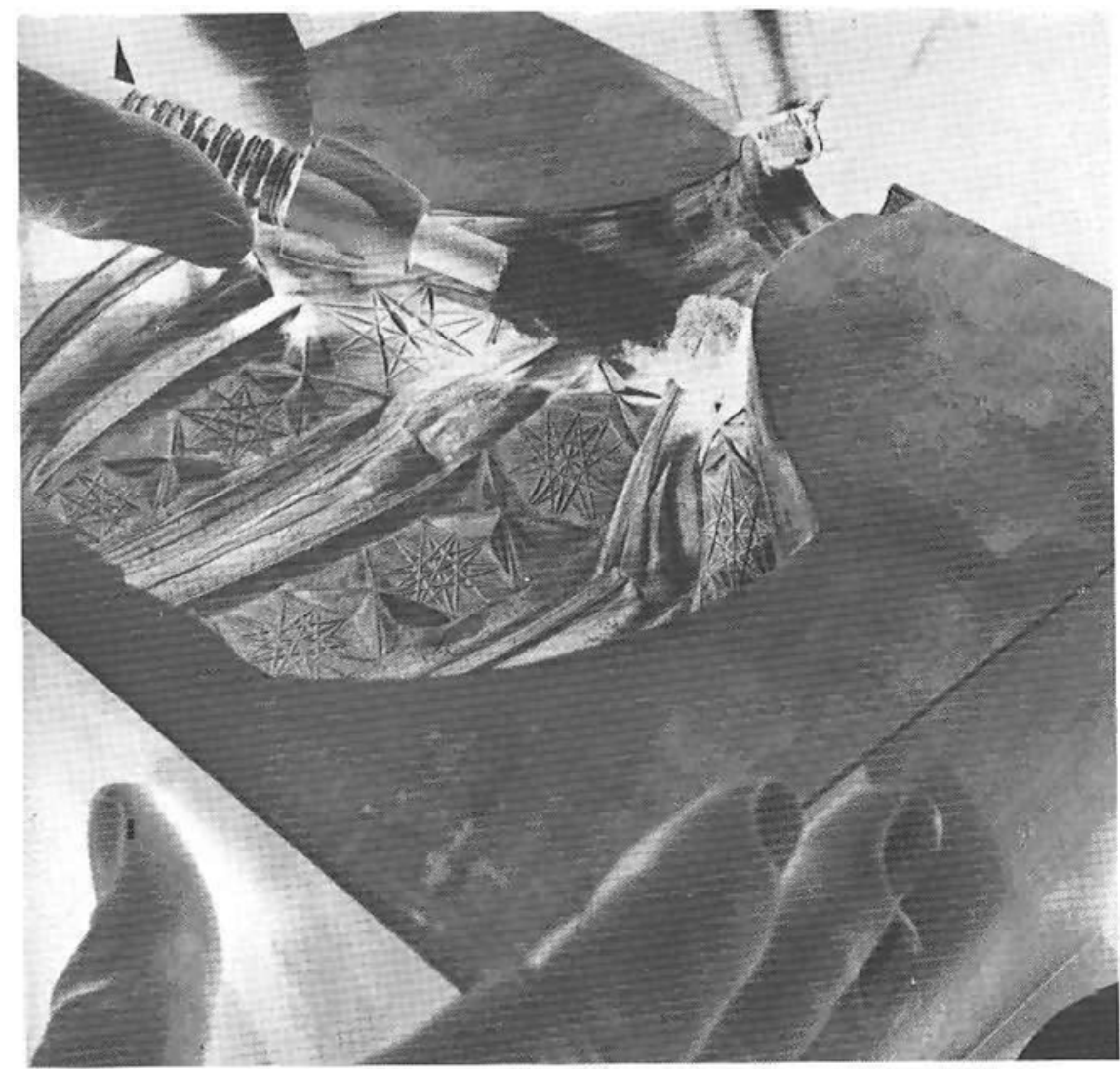

commutator surface, followed by rhodium and a final flash of gold, not only lengthens life, but radically reduces operating temperature and radio interference caused by arcing. A typical example is the commutator on the booster pump on Sud Aircraft CVL-VI-R, where the life of the part was doubled.

In the marine field, similar components have been restored and their performance improved by selective gold, gold-plus-silver, or rhodium-plus-gold plating. An example of a marine application involves replating of cylinder liner adaptor faces and seatings on Napier Deltic Engines. In order to combat corrosion of the spot faces on the liner, the area is electroplated with tin during production by conventional means. After assembly or during repair, it was found that the addition of 0.0002 inch of gold plate to the tin layer enhanced corrosion resistance. Similar operations have been carried out on other parts of cylinder liners, such as in the threads and on the seatings for the nozzle air start and blanking plug adapters. Selective plating has been approved by Lloyd's Register of Shipping.

\section{As an Underplate}

Selectively plated gold is frequently used as an underplate for silver, rhodium and other metals. Since silver deposits by immersion, a strike is required to prevent the formation of poorly adherent deposits. Selective silver plating does not require a silver strike; instead, a thin colour flash of gold will provide a surface more noble than silver. Silver can then be applied with excellent adhesion and without immersion deposits. This technique has proved so successful that several U.S. companies now specify a dilute cyanide gold bath as a pre-plate prior to conventional silver plating.

Rhodium solutions are highly acidic and tend to attack underlying metals. Such attack not only destroys lustre, but contaminates the rhodium solution, making subsequent deposits dark in colour. This problem can be overcome by a nickel underlayer, but nickel in thin deposits tends to be porous; a thin flash of gold serves as a superior pre-plate. Gold has also been used as a pre-plate under nickel to reduce porosity for engineering applications where porosity is detrimental.

\section{Miscellaneous Applications}

There exist many other applications for selective gold plating. Gold plated bus bar connections are not uncommon for specialised types of work. Normally, the connections are tin or silver plated to provide positive contact. However, in a chlorine plant, chlorine gas tends to attack the silver. A deposit of 
0.0001 inch of gold on the copper bus bar provides a superior contact area.

Gold plating has also been used selectively to fill pinholes and reduce porosity. A particular example is in a very sensitive low pressure safety valve used in a satellite system. The entire device, fabricated from 0.0004 inch thick aluminium stock, was made nonoperative by a pinhole. Localised gold plating successfully closed the hole so that the part could be returned to service.

In a sealing operation of a different nature, low temperature diffusion seals at gold-indium plated interfaces (equivalent in bond strength to a goldcopper weld) have been obtained at 370 to $400^{\circ} \mathrm{F}$ with a 30-minute time cycle.

\section{Summary}

High speed selective gold plating provides an additional tool for the plating industry. While not an economical procedure for most high production applications, it provides a simple ancillary technique for applications which involve special problems

In evaluating this technique, platers should strive not to restrict their thinking only to retouching and doctoring. Nor should they conclude a priori that, since selective plating normally requires manual manipulation, it does not lend itself to some types of production.

If these two prejudices are overcome, intelligent industrial platers will find selective plating an excellent money and time saving device for a wide variety of applications in electronics, plastic moulding, aircraft and marine maintenance, and numerous other industries. All that is required is an awareness of possible applications and a willingness to learn the procedures for a somewhat different approach to electroplating. As the process becomes more generally known both plater and user should benefit. 